\title{
ARTÍCULOS
}

\section{LOS PRIMEROS GIMNASIOS HIGIÉNICOS: ESPACIOS PARA SANAR Y CORREGIR EL CUERPO}

\author{
THE FIRST HYGIENIC GYMS: SPACES TO HEAL AND CORRECT THE BODY \\ Miguel Vicente-Pedraz ${ }^{1}$ \\ Universidad de León \\ Xavier Torrebadella-Flix ${ }^{2}$ \\ Universitat Autònoma de Barcelona
}

Recibido: 13 de febrero de 2018; Aprobado: 5 de abril de 2018. Publicado online: 15 de marzo de 2019

Cómo citar este artículo / Citation: Vi cente-Pedraz, Mi guel y Xa vier To rrabedella-Flix. 2019. «L os primeros gi mnasios hi giénicos: espacios para sanar y corregir el cuerpo». Disparidades 74(1): e011. doi: <https://doi.org/10.3989/dra.2019.01.011>.

RESUMEN: Los primeros gimnasios higiénicos, fundados en la década de los años sesenta del siglo XIX, constituyeron un efectivo respaldo a una cultura corporal que, particularmente en Cataluña, empezaba a ofrecer elocuentes signos de diferenciación social entre los miembros de la burguesía. Las reciprocidades ideológicas y culturales que mantenían los usuarios del gimnasio sirvieron de caldo de cultivo para la propagación de las emergentes prácticas y discursos, tanto higiénicos y terapéuticos como de autodominio y de esparcimiento, los cuales, basados en la ejercitación física, supondrían un importante dispositivo para la afirmación de clase.

Mediante cotejo documental acometemos un análisis de corte socio-crítico. Concluimos que la actividad de los gimnasios decimonónicos, especialmente los de Barcelona, dio lugar a una embrionaria cultura física privativa que operó como plataforma de socialización y moralización físicas de la burguesía. A la vez, establecemos conexiones entre ese proceso y la primitiva penetración del sport, reconocible sobre todo en la adecuación de los principios fundadores de este a los intereses de clase.

PALABRAS CLAVE: Gimnasio; Gimnástica; Cultura Corporal; Masculinidad; Barcelona.

ABSTRACT: The first hygienic gymnasiums, founded in the eighteen sixties, were an effective support for a body culture that, particularly in Catalonia, began to offer eloquent signs of social differentiation among members of the bourgeoisie. The ideological and cultural reciprocities maintained by gym users served as a basis for the propagation of emerging practices and discourses, both hygienic and therapeutic, as well a s self-control and recreation, which, based on physical exercise, wo uld become an important device for the affirmation of class.

Through a documentary comparison, a socio-critical analysis of the venue and use of gyms is undertaken. It is concluded that the activity of nineteenth-century gymnasiums, especially those in Barcelona, gave rise to an embryonic privative physical culture that operated as a platform for the socialisation and moralisation of the bourgeoisie.

KEYWORDS: Gymnasium; Gymnastic; Body Culture; Social Identity; Masculinity; Barcelona.

Copyright: (C) 2019 CSIC. Este es un artículo de acceso abierto distribuido bajo los términos de la licencia de uso y distribución Creative Commons Reconocimiento 4.0 Internacional (CC BY 4.0).

1 Correo electrónico: mvicp@unileon.es. ORCID iD: <https://orcid.org/0000-0002-9131-7876>.

2 Correo electrónico: xtorreba@gmail.com. ORCID iD: <https://orcid.org/0000-0002-1922-6785>. 


\section{INTRODUCCIÓN}

Durante la década de los años sesenta del siglo XIX, el ambiente cultural catalán se vio favorecido por la apertura de varios establecimientos privados que, aun con diferentes formas de reclamo publicitario, ofrecían una novedosa práctica corporal, bajo la promesa de ayudar a mantener o recuperar la salud a sus usuarios. Se trataba de los gimnasios higiénicos que en Europa central y Francia llevaban algunas décadas ofreciendo sus servicios, sobre todo, a los miembros de las clases más pudientes.

A diferencia de los gimnasios estatales, particularmente los militares y los escolares - de vocación formativa y de adoctrinamiento y donde los destinatarios eran ciudadanos que acudían mediante reclutamiento forzoso-, los gimnasios higiénicos privados habían de ganarse la clientela persuadiendo a la ciudadanía de los provechos del ejercicio físico; un ejercicio que, por otra parte, debía mostrar credenciales de refinamiento y racionalidad frente a la naturaleza popular y callejera del acrobatismo. A tal efecto, desde muy pronto, sus directores desplegaron una intensa propaganda dirigida particularmente a los sectores más acomodados de la burguesía urbana la cual, además de ser la clase social económicamente más próspera y culturalmente más dinámica, sus integrantes llevaban tiempo interesándose por todo tipo de actividades y recreaciones corporales novedosas, a la vez que distintivas, entre las que también se encontraban las incipientes manifestaciones deportivas llegadas de Inglaterra y Francia.

Indudablemente, el propósito consciente de los usuarios de estos establecimientos era desarrollar la fuerza o la agilidad, poner a prueba la resistencia y la virilidad, enderezar la figura o conjurar sus temores hacia el raquitismo $u$ otras dolencias; frente a ellos se publicitaban los gimnasios tanto en cartelería como en anuncios de prensa. Sin embargo, y a la vez que todo ello, entre los adeptos a la gimnasia empezaba a tomar forma la idea de ejercitación como entretenimiento; empezaba a desarrollarse una emergente concepción del cuidado de sí hermanado con el ocio que, desde el punto de vista sociológico, tendría importantes repercusiones más allá de lo que suponía la aparición de una moda o la constatación de una nueva costumbre. A este respecto, sostenemos que particularmente la nueva afición gimnástica se revelaría como un factor concurrente en el proceso de conformación de la burguesía en la medida en que la apariencia corporal $-y$ con ella las relaciones intra e interpersonales que se despliegan en torno al uso del cuerpo- empezaba a ser un baluarte de la identidad y diferenciación tanto individual como colectiva. El proceso de difusión hacia abajo permitiría que otras capas sociales fueran accediendo paulatinamente a las prácticas corporales higiénico-recreativas según una pauta por la que la gimnástica iría perdiendo potencial distintivo pero, a la vez, auspiciada por la medicina y la educación (Vicente-Pedraz y Torrebadella-Flix 2017), facilitaría la generalización de unos gustos cada vez más elaborados en el seno de una clase social que ya ejercía el dominio económico y pugnaba por el dominio cultural; es decir, se revelaría como un potente catalizador de una cultura física que aspiraba a ser hegemónica.

En todo caso, la desventaja que en términos de distinción pudo tener el proceso de difusión social de las prácticas gimnásticas entre los miembros de las clases populares se vería compensado, y con creces, con la ventaja que suponía para las clases dirigentes poseer una herramienta, al fin y al cabo, normalizadora y disciplinaria del proletariado; en términos foucaultianos, una herramienta que aumentaba las fuerzas del cuerpo en términos económicos de utilidad y las disminuía en términos políticos de obediencia (Foucault 2005: 142). A este respecto, el desarrollo de la práctica gimnástica - de movimientos estructurados, previsibles, rectilíneos - frente a los juegos de la calle y las muy populares actividades funambulescas - de naturaleza espontánea y en cierto modo trasgresora- puede ser visto como una metáfora del orden social y económico que se impone con la modernidad. Por otra parte, nos hacemos eco del planteamiento de Georges L. Mosse (2000) en cuanto que sitúa las prácticas gimnásticas decimonónicas en los intersticios del proceso de construcción de la masculinidad moderna; esta, como parte del idealizado retorno a la cultura del cuerpo sobre la que se fueron conformando los estereotipos corporales burgueses, el masculino y el femenino.

Teniendo como referencia de análisis un constructivismo híbrido entre la teoría del proceso de la civilización de Norbert Elias (1987) y la del papel mediador del habitus en la configuración social de Pierre Bourdieu (1988), planteamos que en el desarrollo y consolidación de la costumbre burguesa de acudir al gimnasio, lo más significativo fue la puesta en marcha de mecanismos de diferenciación de clase mediante la acreditación o exhibición de ciertos usos singulares y en gran medida privativos del cuerpo. En dichos 
usos, la ejercitación propiamente dicha solo era el elemento aglutinante en torno del cual se fueron desarrollando nuevos consumos higiénicos (frecuencia del lavado, desarrollo del baño y la ducha), así como cosméticos y de vestuario, alimenticios, estéticos, etc., y también la exhibición de una pose y de una gestualidad aprendidas en las que cabe incluir la (re) definición de la sexualidad. Todo ello al servicio de una nueva y diferenciadora - a menudo excluyenteimagen del cuerpo respecto de la que el gimnasio era un lugar de intercambio práctico y simbólico: un lugar de experimentación, de puesta a prueba, de nuevos usos corporales $y$, por supuesto, un lugar de afirmación de la posición ocupada en el espacio social.

De Elias (1987 y 1990) nos apropiamos de la idea de transformación de las costumbres como proceso de desarrollo del autocontrol emotivo y del refinamiento paulatino de la conducta como resultado de la pugna entre lo viejo y lo nuevo, lo común y lo diferenciador, cuyo análisis pone sobre la mesa el proceso de individualización ligado a la urbanización y burocratización de la modernidad; particularmente, tenemos en cuenta su modelo teórico según el cual uno de los motores de la civilización es la permeabilidad de las costumbres propia de la vida en común, espoleada por las tendencias a la diferenciación y autoafirmación social (sobre todo de las clases dominantes) y a la promoción social (en las clases populares) a través de la apariencia corporal. De Bourdieu asumimos sobre todo la apreciación de que existen estructuras objetivas, independientes de la conciencia, capaces de determinar las prácticas y las representaciones; asimismo, la idea de que los patrones de percepción, pensamiento y acción sociales que determinan el habitus son productos sociales de manera que «las distancias sociales están inscritas en los cuerpos..." (Bourdieu 1988: 132) y, por supuesto, la noción de que la distribución de las propiedades corporales no son independientes de la distribución de las demás propiedades entre las clases sociales (Bourdieu 1986).

Por otra parte, tomamos en consideración el planteamiento de Michel de Certeau según el cual las prácticas que tienen lugar en un sistema urbanístico no ocupan, sino que construyen el espacio en una relación simbiótica con dicho sistema en tanto que espacio practicado, un lugar «animado por el conjunto de movimientos que ahí se despliegan» (De Certeau 2000: 129). En este sentido, la proliferación de gimnasios higiénicos en los principales enclaves urbanos entre mediados y finales del siglo XIX cabe interpretarla como un cruzamiento de movilidades arquitectónicas, sociales, culturales, ideológicas, etc., donde el sujeto que practica (ejercicios gimnásticos) es una dimensión más en el proceso de configuración del espacio social.

Aunque la apertura de gimnasios higiénicos privados en España se constata también en otros grandes núcleos urbanos, fueron sobre todo Barcelona y Madrid las poblaciones que actuaron como punta de lanza de lo que luego sería un fenómeno generalizado. Pues bien, con el propósito de descifrar los códigos sociales y culturales subyacentes al contexto catalán y particularmente el barcelonés, en una primera fase de la investigación procedimos a una exhaustiva revisión tanto de las fuentes primarias proporcionadas por Torrebadella-Flix (2011b) - como de las secundarias disponibles. En la segunda fase del trabajo llevamos a cabo una búsqueda de datos históricos relevantes que nos permitiera, mediante ordenación, selección, cotejo y análisis, una contextualización lo más precisa posible del proceso. Para ello hemos utilizado los accesos abiertos de los fondos digitalizados de la Hemeroteca de la Biblioteca Nacional, ARCA - Archivo de Revistas Catalanas Antiguas-, los de la Biblioteca Virtual de la Prensa Histórica y los del Fondo Local de las Publicaciones Periódicas Digitalizadas de la Diputación de Barcelona.

Como estrategia expositiva, hemos dividido el artículo en siete apartados. Tras esta introducción, en el segundo apartado acometemos el surgimiento de la gimnástica como materia educativa en algunos de los colegios privados de mayor prestigio; en el tercero, subrayamos algunos aspectos relevantes sobre la producción bibliográfica sobre la que se legitimó la nueva práctica. En el apartado cuarto, debatimos sobre el auge de las compañías gimnástico-acrobáticas y presentamos de manera descriptiva lo que, a la luz de los datos recogidos, constituyó la paulatina configuración de los primeros gimnasios higiénicos de Barcelona. El quinto apartado, previo a las conclusiones, nos sirve para establecer de manera genealógica la mecánica que subyace a la conformación moderna del gimnasio higiénico. Particularmente, se discute sobre los dispositivos sociales y culturales que dieron origen a la invención del gimnasio como espacio de regeneración física y moral que, no obstante, sirvió de catalizador simbólico y práctico a una burguesía 
que supo encontrar en las prácticas corporales privativas de clase una forma de ostentar su hegemonía. Prestamos atención especial a los procesos de conformación social de la masculinidad ligada a la práctica gimnástica.

\section{LA GIMNÁSTICA AL SERVICIO DE LA SALUD Y LA EDUCACIÓN}

Aunque desde principios del siglo XIX hubo iniciativas gubernamentales para impulsar la gimnástica en España, solo a partir de que el valenciano Francisco Amorós (1770-1848) adquiriera cierto renombre entre los gimnasiarcas franceses, y su obra comenzara a difundirse en la península, empezó a notarse un cambio significativo en el panorama gimnástico español (Torrebadella-Flix 2014a).

Indudablemente, el caldo de cultivo sobre el que germinaron las prácticas gimnásticas, tanto en Europa como en España, estaba bien nutrido por un imaginario médico-político disciplinario que, en su lucha contra la degeneración de la raza, había hecho de la molicie, el apoltronamiento y el onanismo sus principales caballos de batalla; contra todos ellos, el ejercicio físico, particularmente si era intenso, regular y rectilíneo - de modo que conjugara rectitud física y moral (Vicente-Pedraz y Brozas 2017)-, era visto como el más eficaz de los antídotos (Torrebadella-Flix y VicentePedraz 2016; Vicente-Pedraz y Torrebadella-Flix 2015) y como tal lo daba a conocer la ciencia médica en lo que se puede considerar la antesala del eugenismo europeo. Por otra parte, no se puede despreciar la incidencia que en la consolidación de la gimnasia tuvo la idealización romántica de la estética grecolatina cuyos cuerpos, cincelados en la palestra, habían empezado a servir de modelo sobre todo a los miembros más ilustrados y emprendedores de la sociedad.

En todo caso, la incipiente moda de la ejercitación corporal encajaba plenamente con las emergentes estéticas corporales (Chaline 2015), primero aristocráticas y luego burguesas, para las que la figura del gentleman se mostró paradigmática (Cercós y Calvo 2013). Y todo ello en fructífero consorcio con el proceso de medicalización que desde principios del siglo XIX fue penetrando en los intersticios de la vida cotidiana, sobre todo familiar, como un mecanismo social más de tutelaje (Donzelot 1998) y buen gobierno tanto corporal como moral. A este respecto, también la proliferación de manuales de urbanidad y cortesía, de buenos cuidados, de costumbres saludables y morales, de higiene y de gimnástica, en su mayoría escritos por médicos, contribuirían decididamente a legitimar las virtudes de la gimnástica presentada como ciencia de los ejercicios de forma razonada, ortopédica, higiénica y médica (Heiser 1854; Schreber 1861).

En ese contexto, el gimnasio, que se mostró inicialmente como un elemento de lujo, podía cubrir las emergentes demandas higiénicas de las élites sociales a la vez que confería a sus usuarios cierto carácter diferenciador. En Francia Hippolyte Triat (1813-1881), gimnasiarca que cobró protagonismo tras la muerte de Amorós, tuvo la idea de instalar un completísimo gimnasio que se sustanció en el denominado Grand Gymnase de París; bajo el lema «Para la regeneración del hombre», el Grand Gymnase fue abierto en 1849 en la Avenida Montaigne, 36 -Champs Élysées - (Féval 1852: 2). El establecimiento, que según Andrieu (1992) fue un modelo a imitar en toda Europa, consiguió captar la atención de la alta sociedad parisina, algunos de cuyos miembros encontraron en él sobre todo un escaparate donde confrontar sus veleidades de distinción. Este gimnasio, tal vez junto con el que abriera Eugenio Paz (1836-1901) en 1865 en la calle des Martyrs, 34 -aunque traspasado a Chrétien Heiser en los años ochenta (Sánchez y González de Somonano 1884)-, se puede considerar como el caso más paradigmático del desarrollo de este tipo de establecimientos, entonces al alcance y del gusto de muy pocos.

En España, a mediados de siglo ya se habían establecido algunos gimnasios particulares en algunos colegios y en las guarniciones militares de ciudades como Barcelona, Madrid, Bilbao, Burgos, Cádiz, Figueras, Guadalajara, Lleida, Mataró, Sevilla, Palma de Mallorca, Puerto de Sta. María, Toledo o Valladolid (Torrebadella-Flix 2012a y 2013c).

Aunque se ha sostenido que la cuna del movimiento gimnástico español se sitúa en Madrid, dándose como cierto que el germen del mismo fue el gimnasio que fundara Francisco Aguilera, Conde de Villalobos, en 1842 (Piernavieja 1962; Cruz 2014), hoy podemos afirmar que con anterioridad a esa fecha ya había gimnasios higiénicos en Barcelona, Valencia y Sevilla (Torrebadella-Flix 2013a y 2013b; TorrebadellaFlix y Arrechea 2015). Antes de 1840 ya había algunos gimnasios en Barcelona abiertos al público en general y, asimismo, los mejores colegios los habían instalado para sus distinguidos estudiantes, a cuyo efecto con- 
trataron a los más renombrados profesores del momento. De entre los colegios que en 1840 contaban con un gimnasio destacan el Instituto Barcelonés y el Colegio Carreras (Torrebadella-Flix y Arrechea 2015). En el área metropolitana de la ciudad cabe señalar el Colegio Valldemia de Mataró, abierto por el padre Coll algo más tarde, en 1854, calificado como uno de los mejores colegios de España, justamente, por completar la formación con una celosa educación física auxiliada con un completísimo gimnasio al aire libre (Gurrera 1995). La influencia que ejerció este colegio fue muy significativa en la zona puesto que al cabo de una década ya eran varios los colegios de Mataró que disponían de gimnasios; uno era el Colegio Mataronés («Colegio Mataronés» 1864) de primera y segunda enseñanza, y otro el de la Escuela Pía Santa Ana que, en 1865, según citaba la Revista Mataronesa, era: "... uno de los más bien montados que se han ofrecido a nuestra consideración, pudiendo trabajar en él simultáneamente multitud de niños, por la mucha variedad de sus aparatos» (Gurrera 1995: 23).

Por su parte, en el Colegio de San Ignacio de Manresa, que funcionaba como instituto de segunda enseñanza desde 1847, los padres de la Compañía de Jesús también dispusieron la impartición de clases de educación física. En 1858 se estableció una cátedra de gimnástica que estuvo dirigida por los hermanos Braquets, conocidos gimnasiarcas profesionales provenientes del espectáculo gimnástico-acrobático («Gimnasia» 1858). Con todo, se puede afirmar que la gimnástica, antes de que fuera una disciplina escolar con carácter oficial, ya aparecía en algunos de los institutos de segunda enseñanza catalanes: Figueras, en 1845; Manresa, en 1858; Lérida, en 1859; Tarragona, en 1863; y Barcelona, en 1865.

Superada la primera mitad del siglo XIX, los gimnasios, aunque con diferente casuística e incluso diferente estructura según se tratara de espacios educativos o higiénicos, ya se habían convertido en lugares de reunión alrededor del ejercicio corporal sistematizado donde no dejaron de proliferar aparatos y métodos con los que recuperar, mantener o acrecentar las energías de la máquina humana. Entre los métodos o sistemas más populares cabe destacar el del sueco Pehr Henrik Ling por su amplia expansión geográfica y el del célebre Francisco Amorós, los cuales irían ajustando sus procedimientos a los ámbitos educativo, higiénico-médico, militar o civil.
Inoculado el germen del gusto por la gimnástica en los sectores más dinámicos de la élite, en la década de los años sesenta se asiste a una verdadera eclosión fundacional de gimnasios higiénicos en casi todas las grandes ciudades. En el caso de Cataluña se concreta en, al menos, dieciocho inauguraciones: Tomás Casals (Lleida, 1859), Moratones (Barcelona, 1859), Joaquín Ramis (Barcelona, 1860), José y Luis Vall (Barcelona, 1860), Francesca Vall (Barcelona, 1862), Joaquín BatIle (Reus, 1862), Antoni Moratones (Barcelona, 1863), Juan Estrany (Barcelona, 1863), Daservile y Berthier (Barcelona, 1863), José y Luis Vall (Barcelona, 1863), Francesca Vall (Barcelona, 1863), Francisco Sala (Tarragona, 1863), Pablo Perret (Tarragona, 1863), Juan Milá (Barcelona, 1864), Nicolás Camús (Tarragona, 1864), Federico Clemente (Figueras, 1865), Venús (Vic, 1866), Fidel Bricall (Barcelona, 1868), Antoni Rovira (Barcelona, 1868), Pedro García (Barcelona, 1868) y Tomás Martí (Tarragona, 1869).

Esta concatenación de iniciativas permite afirmar que, efectivamente, a finales de los sesenta los gimnasios ya formaban parte de la fisonomía urbana y empresarial catalana que, como ha sido sugerido ( $\mathrm{Pu}$ jadas 2010; Torrebadella-Flix, Olivera-Betrán y M-Bou 2015), constituyó el caldo de cultivo para la rápida adaptación del deporte en el último tercio del siglo XIX.

\section{LA PRIMERA BIBLIOGRAFÍA ESPECIALIZADA EN TORNO A LA GIMNÁSTICA}

El desarrollo científico y tecnológico, que al calor del crecimiento industrial afectó sobre todo a los grandes núcleos de población, tuvo como consecuencia la revitalización de la vida cultural y, con ella, una creciente demanda de información y de formación. Particularmente, el desarrollo de la medicina y la higiene social, en confluencia con las nuevas preocupaciones en torno a la estética corporal y al disfrute hedonista (Vigarello y Holt 2005), debió incidir en la demanda de obras que se ocupasen de la educación física.

En respuesta a esta necesidad aparecieron los primeros tratados de gimnástica higiénica, médica y educativa. Según Climent (2001) y Torrebadella-Flix (2011b y 2013a), en la década de los sesenta la literatura gimnástica experimentó un importante desarrollo con la irrupción de obras que ayudaron a forjar la gimnástica como campo académico pero también 
como espacio profesional bien identificado. De los primeros momentos destaca el genuino método del Manual de Gimnasia de Sala de Schreber (1861), que se reveló como la propuesta más apta y facilitadora de la gimnástica higiénica, médica, doméstica y escolar (Torrebadella-Flix 2014b); asimismo, el empírico tratado de gimnasia médica del Dr. Busqué (1865) y el tratado Gimnástica médica y Civil del gimnasiarca Carlier (1867), propietario del gimnasio de Santander. Aparecieron también obras propagandísticas como el tratadito del barcelonés Moratones (1863) - plagiado de Amorós-, el opúsculo comercial del gimnasio de Joaquín Ramis (1865) o los folletos promocionales de gimnasios como el que fuera de Juan Goux (1864 y 1866), maestro de esgrima reconvertido en profesor de gimnástica (Figura 1).

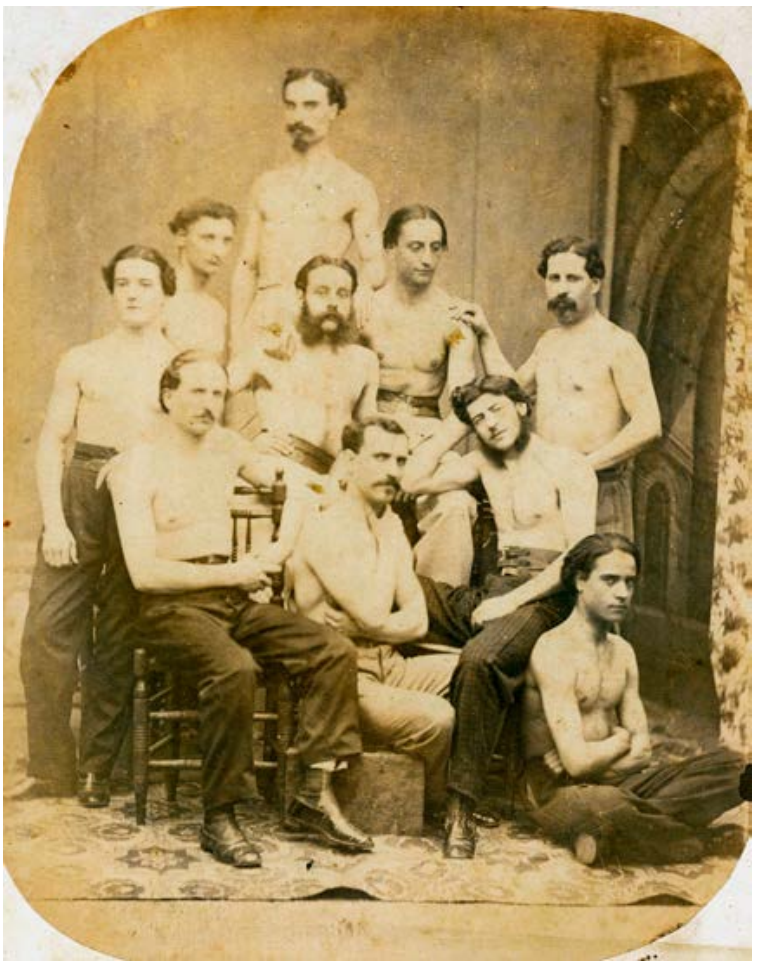

FIgURA 1.-Alumnos del Gimnasio de Joquim Ramis i Taix [sentado en el centro de la imagen], ca. 1861. Fuente: Fons històric Ramis. Museo d'Història de la Medicina de Barcelona

Un tratado singular fue el del gimnasiarca Eugenio Paz (1867), traducido del francés como La salud del espíritu y del cuerpo por la gimnasia, que contribuía a la débil propaganda sobre gimnástica que se estaba iniciando en España (Torrebadella-Flix 2013a). También vio la luz el tratado de Joaquín Lladó y Barceló (compositor y musicólogo: Barcelona, 1834-1878), Nociones de gimnástica higiénica aplicables a las escuelas de instrucción primaria de uno y otro sexo
(1868) que bajo la influencia de la gimnástica de Amorós era presentado como guía para maestros y gozó de una difusión hasta entonces desconocida. Sorprenden las palabras de Lladó (1868) al afirmar que, sin ser la gimnástica obligatoria en la enseñanza, eran pocos los centros escolares donde no se practicaba; una percepción que también compartía el sevillano Salvador López (1873).

En el fragor editorial de este tipo de obras, la charlatanería también tuvo su espacio. Una verdad o consideraciones sobre la utilidad de la gimnástica es un opúsculo de cuarenta y siete páginas en el que Ramis recurría a la visión higiénico-médica de la gimnástica civil a través de un cuadernillo publicitario de su establecimiento fundado en Barcelona en 1860 - Gimnasio Español, Plaza Real, 1 bajos-. En sí, contiene treinta y una cartas dirigidas a Ramis en las que se elogiaban las virtudes del método que empleaba. Las cartas muestran diferentes casos de hombres que mejoraron sus dolencias físicas y enfermedades gracias a la gimnástica: gastritis crónica, tisis, dolores de riñones, hipocondría, inapetencia, trastornos del sueño, dolores de espaldas, debilidad muscular, dolores de cabeza o carencia de vigor. El propósito del opúsculo era difundir las ventajas de la gimnástica frente a los medicamentos y como sustituto de la medicina común donde esta fracasaba: «nos hemos propuesto escribir el presente folleto para trazar, a grandes rasgos, el resultado de nuestras observaciones, poniendo de manifiesto la influencia bienhechora de la Gimnástica, que pudiera muy bien apellidarse Arte regenerador de la especie humana» (Ramis 1865: 3).

En esta época, la Facultad de Medicina y Cirugía de la Universidad Central inició un significativo impulso de concienciación respecto de la importancia de la educación física y la gimnástica. A este impulso contribuyó la presentación de varias memorias o discursos para acceder al grado de doctor. No obstante, pese al voluntarismo de estas primeras expresiones académicas de la moderna gimnástica, se constata en ellas un escaso conocimiento profesional hacia un ámbito de estudio que no dejaba de ser nuevo y que pugnaba, junto a otros conocimientos y prácticas, por ocupar un espacio en los estudios de Medicina (Torrebadella-Flix 2012b). Al lado de los discursos de doctorado, fue muy significativa la publicación de artículos en revistas de diferentes especialidades médicas (Macedo 1860; Aguilera 1865; Busqué 1865; Losada 1865; Salgado 1865a y 1865b). 


\section{DEL APOGEO DE LA GIMNÁSTICA ACROBÁTICA A LA GIMNÁSTICA HIGIÉNICA}

Los primeros gimnasios higiénicos surgen en el momento más álgido de la gimnástica acrobática, una expresión artística de calle y de circo que fue quedando relegada a un espectáculo marginal, aunque inicialmente fue capaz de concitar las expectativas de todas las clases sociales. En su momento de mayor apogeo, en Madrid y Barcelona los circos y teatros se disputaban la presencia de los mejores especialistas internacionales (Torrebadella-Flix 2013b). Las proezas del gimnasta Jules Léotard (1838-1870) -como, por ejemplo, la primera vez que realizó un salto de trapecio a trapecio, en París, en 1854) - eran divulgadas por la prensa de toda Europa. La popularidad del espectáculo circense iba en aumento y las compañías de funambulismo francesas e italianas recorrían el continente; también, como señalaba Masriera (1924), visitaban tierras españolas.

De la época se conservan importantes referencias de otras hazañas y personajes que así lo atestiguan. Por ejemplo, el acróbata francés Jean François Gravelet, conocido como Blondin (1824-1897), recibió reconocimiento mundial por cruzar sobre el cable las cataratas del Niágara en 1859. En 1863 visitó Barcelona y deleitó al público con varios espectáculos en la Plaza de Toros. Todavía en este momento, en las funciones que realizaba, actuaban gimnastas reconocidos como es el caso de los hermanos Camús y los señores Coll y Venus, algunos de los gimnastas catalanes más populares del momento (Dalmau 1947). Estos gimnastas realizaban ejercicios de equilibrios, acrobacias con saltos y volteos mortales, contorsiones y dislocaciones, ejercicios de fuerza, de agilidad en las anillas, en las escaleras, en la percha o en los trapecios («Diversiones públicas» 1863); es decir, una combinación de ejercicios a caballo con el arte. Pero la separación entre la acrobacia y la gimnasia higiénica estaba en marcha. Estaba en marcha en la medida en que la primera no podía dejar de remitir a una cultura popular, espontánea y en ocasiones subversiva (VicentePedraz y Brozas 2017) frente a un modelo corporal que llevaba tiempo haciendo alarde de los valores de la regularidad y la rectitud y que fraguó cuando la burguesía empezó a tomar conciencia del valor de la apariencia - no solo de la fisonomía, sino también de las actitudes, de los hábitos, de los gestos y de los gustos - como dispositivo diferenciador.
$Y$ no cabe duda de que frente al saltimbanqui y el volatinero, a menudo representados como símbolo de la anticultura, la rectitud del cuerpo del gimnasta y la regularidad de sus movimientos remitían a una modalidad de la conducta, la del autodominio, que la burguesía reclamaba para sí.

No obstante, la pugna que libraron la acrobacia y la gimnasia higiénica y que se saldaría con el paulatino afianzamiento social de la última - de movimientos rectilíneos, regulares, atemperados y previsiblesno terminó absolutamente con la afición a la acrobacia ni siquiera entre los miembros de la alta sociedad. Como espectáculo arraigado que era, pasaría tiempo hasta que su práctica quedara definitivamente escindida de la gimnástica higiénica y relegada a la marginalidad y los gustos de las clases más populares.

De hecho, durante décadas, los practicantes transitaron de una a otra según dictaban las tendencias y la cotización de cada una. Así, una de las ocupaciones profesionales con la que muchos funámbulos y gimnastas completaban su sostenimiento, la instrucción en colegios, fue testigo de una importante controversia en el origen mismo de lo que luego sería la educación física escolar: la controversia sobre si la gimnasia acrobática, frente a la gimnasia higiénica, era indicada en el entorno educativo y qué traducía al lenguaje médico-pedagógico - un lenguaje técnico-, lo que no era sino la pugna entre dos modelos corporales, pero también sociales y culturales, distintos. A ese respecto, Torrebadella-Flix (2012b) ha mostrado cómo los argumentos que entonces fueron esgrimidos contra la gimnasia acrobática en las escuelas, tales como la falta de formación de los profesores, la peligrosidad de los ejercicios, entre otros, venían a desacreditar un modelo de cuerpo y de actividad corporal espontáneo, libre, artístico -en ocasiones provocador - frente al arquetipo en alza de la rectitud, la regularidad y la racionalidad.

En todo caso, el espectáculo gimnástico acrobático continuaría su andadura no sin importantes hibridaciones con su competidor más académico, la gimnástica higiénica, e incluso con la emergente gimnasia escolar. A principios de la década se destacó Juan Milá, un joven acróbata formado por Ramis, llamado el «rey de la gimnasia» que competía en agilidad con el mismo Léotard. Se cuenta que Milá recibió preparación específica en los gimnasios de Alemania y Suiza y que luego fue exhibiendo sus habilidades gimnásticas por toda España. Asimismo, Milá dispuso de 
un gimnasio en Barcelona, que sostuvo entre 1864 y 1868, porque como señalaba Dalmau (1947: 45): «Siempre hubo, entre los jóvenes barceloneses del pasado siglo, afición a la gimnasia. La popularidad de los artistas de circo tentaba a muchos que soñaban en emular sus proezas. La gimnasia higiénica no se conocía apenas y, en cambio, privaba la gimnasia atlética».

Pero la batalla por la implantación de la gimnasia higiénica no solo se libraba en el ámbito de la práctica privada. Sin el beneplácito institucional y particularmente el educativo, probablemente su implantación hubiera sido otra y desde luego más lenta. Aquí la defensa de la gimnasia escolar, a la postre educación física, jugaría un papel destacado en la conformación de los nuevos hábitos. El destacado higienista Carlos Ronquillo (1870) denunciaba ante la Sociedad Barcelonesa de Amigos de la Instrucción el triste abandono en el que se encontraba la educación física y, al respecto, proponía introducir la gimnástica en las escuelas municipales de Barcelona tal y como se venía haciendo en las escuelas inglesas. Sostenía que solo de ese modo se podían resolver los problemas de salud de una población infantil débil por la falta de ejercicio físico y las malas costumbres posturales. Ronquillo proponía dar agilidad y robustez al cuerpo mediante los juegos corporales pero, también, con una gimnasia higiénica.

Así, si en los primeros gimnasios la gimnasia ortopédica e higiénica compartía espacio con la acrobática y recreativa aún en boga, a partir de la década de los sesenta, la desacreditación del funambulismo provocó una significativa transformación de estos establecimientos para adaptarse a un público que cada vez más demandaba la gimnasia higiénica. Pasada una década, en el gimnasio de Estrany se podía leer como reclamo publicitario que «ya han pasado aquellas rancias preocupaciones de nuestros abuelos que solo veían en la gimnástica los mezquinos y ridículos ejercicios de los saltimbanquis» (J. A. de T. 1868: 805); una clara muestra de la transición que se estaba operando, al menos conceptualmente, entre el arte del acrobatismo y el de la gimnasia que culminaría con la elevación de esta última a la categoría de ciencia y de utilidad pública según la pretensión de algunos médicos y pedagogos.

La pervivencia de los establecimientos, cuya diversidad respondía en parte a la variedad de demandas en torno a la práctica física y en parte a que el mercado gimnástico aún estaba en fase de exploración, mostraba que los ejercicios higiénicos empezaban a ser algo más que una moda pasajera; era el resultado de una significativa y creciente afición al cultivo del cuerpo que había llegado a la ciudad para quedarse.

La gimnástica estaba de moda en toda Europa (Vigarello 2006) y a ello contribuyó no poco la buena acogida que tuvo en los círculos médicos, algunas de cuyas obras en materia terapéutica - como las de Ribes (1860), Coca (1862) o Busqué (1865) - tuvieron la audacia de prescribir ejercicios gimnásticos para diversas dolencias (Vicente-Pedraz y Torrebadella-Flix 2017):

Una de sus ventajas [del ejercicio gimnástico] es la de poder limitar su acción mejor que la de un agente farmacológico puesto que está sometido a nuestra voluntad. Los ejercicios por sí solos pueden constituir hasta cierto punto un método de tratamiento y son en muchos casos auxiliares indispensables de los medicamentos (Ribes 1860: 652).

Y si en Europa era común, al menos también lo era en Cataluña. El cotejo de los datos de la ciudad de Barcelona con los de otros centros urbanos pujantes como Madrid permite colegir que antes de culminar la década de los sesenta, Barcelona ya era la primera ciudad gimnástica de España. Había gimnasios para atender las diferentes aplicaciones en boga, ya en el campo militar, en el médico-ortopédico e higiénico o, bien, para una intencionalidad higiénica-educativa o simplemente recreativa, como en el caso de la gimnástica acrobática. Por la ciudad pasaron varios discípulos de Amorós que ejercieron de profesores de gimnástica. Fueron especialmente conocidos los gimnasios de Barrios, Mansó, Berthier, Vall o José Florencio Quadras, entre otros (Torrebadella-Flix y Arrechea 2015). En este último, conocido como Círculo Gimnástico Barcelonés, hacia finales de la década de los cincuenta, se formaron importantes gimnasiarcas como los profesores Vignolles o Joaquín Ramis. Ubicado en los sótanos del número 1 de la Plaza Real -en cuya planta baja se encontraba el Café Universo-, servía de punto de reunión en el que algunos jóvenes aficionados a la vez que se ejercitaban se empleaban en entretenimientos de tipo literario y artístico tal como refiere el manuscrito El Trapecio, semanario guasón redactado por una compañía de titiriteros del Círculo Gimnástico Barcelonés (1860). En 1860 este local pasó a ser propiedad de Joaquín Ramis Taix, convirtiéndose en el primer gimnasio higiénico de Barcelona (Masriera 1924). 
Además del Círculo Gimnástico, Quadras, que también llegó a impartir clases de gimnasia en diferentes colegios de Barcelona, instaló en 1862 un nuevo gimnasio en la calle Nueva de San Francisco, números 11 y 13 , donde hacia 1866 impartía clases de acrobacia por las que cobraba «treinta reales al mes a los hombres y sesenta reales a las mujeres»; posteriormente, el gimnasio fue dirigido por el Dr. Casademunt «... que imprimió a sus enseñanzas una orientación más hacia la gimnasia higiénica» (Dalmau 1947: 46).

Por lo que se refiere a sus más destacados discípulos, Alfonso Vignoles ya dirigía en 1859 el magnífico gimnasio del Colegio Carreras - establecido en Sant Gervasi y propiedad del señor Carlos Carreras de Urrutia (1807-1873) - ${ }^{3}$. De este establecimiento se dijo que era el más completo que hasta la fecha había visto. A su vez, Vignolles, que como hemos dicho aprendió el oficio con Quadras - del que en 1860 se separó para trasladarse a Madrid (R. F. 1882; "Sueltos» 1882) - , tuvo como discípulo aventajado al profesor de gimnástica David Ferrer y Mitayna (R. F. 1882). Este, como para dar mayor porte y dignidad a la escuela de la que procedía, decía del profesor Quadras que era un hombre «... con criterio formado en el trato de hombres notables en ciencias y letras que frecuentaban su gimnasio, sabía distinguir la gimnasia acrobática de la verdaderamente útil, y hacia esta avivada la afición de sus alumnos» (Ferrer y Mitayna 1901: 16).

La Guía de Barcelona de 1863, aparte del gimnasio de Ramis, mencionaba seis gimnasios más: DasserviIle y Berthier, calle Ramalleras, 16; Juan Estrany, calle Beato Oriol, 4; Antonio Moratones, calle Magdalena, 3; José Florencio Quadras, calle Nueva de San Francisco, 11; Luis Vall, calle Guardia, 15; Joaquín Ramis, calle Colón, 3 y el "Gimnasio especial para señoras» a cargo de Francisca Vall, calle Palma San Justo, 14 (J. A. S y M. LI. 1863). Además, hay noticia del que fuera Gran Gimnasio Europeo, Higiénico y Ortopédico, en la calle Rull, 2, dirigido por los hermanos Vall, José, Luis y María, que anunciaba su establecimiento en el Lloyd Español (30 nov. 1865: 4) para la «Regeneración del hombre». Contaban con unos abonos de

3 En el Colegio de Carlos Carreras de Urrutia 1. $\stackrel{a}{\text { y }}$ 2. $\stackrel{\text { a }}{\text { ense- }}$ ñanza, situado en el Palacio del Conde de Centellas, en el pueblo de Sant Gervasi (Barcelona) fue inaugurado en 1839. Asistían los hijos de las familias acomodadas de Barcelona y en él se establecieron clases de adorno de música y baile. Años más tarde el colegio fue equipado con uno de los mejores gimnasios de Barcelona.
20 reales al mes para los caballeros y 40 reales para las señoras (Figura 2). Asimismo, hay constancia del Gimnasio Modelo dirigido por Manuel Vall Cardona, calle Mendizabal, 17 (Vall 1865).

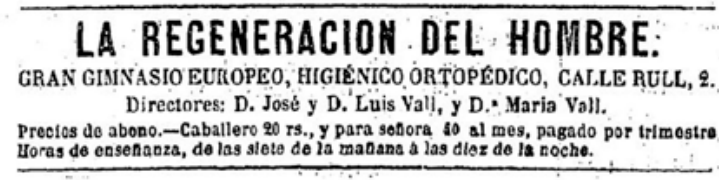

Figura 2.-El Lloyd Español 30 nov. 1865: 4. Fuente: Biblioteca Nacional de España

\section{LA CONSTITUCIÓN DE LA MODA GIMNÁSTICA: ENTRE LA IDENTIDAD BURGUESA Y LA ESTÉTICA DE LA MASCULINIDAD}

Durante el siglo XIX, médicos e higienistas, erigidos en representantes máximos de la salud física $y$, de alguna manera, también en guardianes de la salud moral, fueron tejiendo y dando legitimidad a toda una red de preceptos y de hábitos que permitió extender los dispositivos de la higiene pública al ámbito doméstico. Con el concurso de las inquietudes diferenciadoras de la burguesía urbana en torno a la apariencia física, pero contando con la cada vez más arraigada idea de la relación entre buen gobierno corporal y orden social, iría cobrando fuerza, con sus luces y sus sombras, una medicina social cuyo baluarte ideológico seguía siendo el progreso económico y, con él, el bien común. Si desde la antigüedad la rectitud física fue tomada como el reflejo de la integridad moral (Planella 2006; Nanu y Vicente-Pedraz 2007), en esta época, tal vez por la influencia del puritanismo victoriano y su arquetipo de la compostura -la conducta refinada del gentleman-, el vínculo entre lo ético y lo estético, entre la integridad moral y la apariencia corporal, apuntaba a las ideas de modernidad y civilización; ideas que la pujante burguesía catalana se arrogó, en parte en nombre de la salud, frente a la conducta incontenida y desordenada de las clases subalternas, consideradas depravadas, sucias y peligrosas.

En este contexto, es necesario poner de relieve la importancia que desde mediados de siglo tuvo en toda Europa el discurso de la degeneración física y moral de la especie humana y que, según Mosse (2000) o Vigarello (2005), caló particularmente ente los miembros de la mediana burguesía. 
La asociación entre enfermedades hereditarias y miseria moral, que en Francia había servido a Nicolás Dally (1795-1862) para promocionar la gimnasia racional como antídoto contra el extravío de las costumbres y apoltronamiento de la época (Dally 1848), tuvo eco en la prensa española que también recomendaba "La regeneración física de la especie humana por medio de la gimnasia racional» (1848: 2) alejada del acrobatismo basado en elementos de fuerza y de suspensión del cuerpo.

La medicina oficial española también asumió el discurso de la regeneración física sin mucha controversia. Ya en 1858 De Andrés (1858: 18) alertaba de los peligros en El Consultor Higiénico: «... con la degeneración que vamos observando en la especie humana, pues de fuerte, robusta y atlética que era, háse convertido en raquítica y afeminada», y más tarde se pondría de relieve en diversos discursos de investidura para la obtención del título de Doctor en Medicina (Torrebadella-Flix 2012b). El mismo Ramis (1865: 3) aseguraba que la gimnástica podría llamarse "Arte regenerador de la especie humana», y Eugenio Paz consideraba que la gimnasia racional contribuía a «... facilitar à las generaciones futuras, nuevas vías de salvación; su objeto es legarles la fuerza y la hermosura física, la energía y la calma intelectual, y sobre todo la salud, la salud del espíritu y del cuerpo, es decir, la salud ideal y perfecta» (Paz 1867: 13-14).

La difusión de esta corriente de pensamiento higiénico-moral, sustentada en la aplicación del darwinismo a la comprensión de la sociedad, contribuiría no poco al florecimiento de los primeros gimnasios higiénicos en España (Torrebadella-Flix 2014b). Algunos autores de referencia en la historia de la educación física tales como Spencer (1861) o, en España, Lladó (1868) harían acopio de las máximas de este ideario que en urbes como Barcelona, populosas y plurales, fraguaron tal vez más que en cualquier otro sitio. Como ha señalado Javier Ugarte (2012), la teoría higiénica y moralización del discurso degeneracionista, apoyada en la doctrina moreliana, dio pábulo a aquello que se consideraba pública y privadamente obsceno:

La teoría degenerativa se desarrolla con la vista puesta en unas metrópolis donde comienzan a aparecer, en la segunda mitad del siglo XIX, varones afeminados que se muestran dispuestos a mantener relaciones con otros varones, junto a otras mujeres masculinas que gustan rodearse de otras mujeres y disfrutar de su intimidad (Ugarte 2012: 30).
Los temores que suscitaba la idea de la degeneración física se dejaban sentir con especial inquietud allí donde la actividad industrial y la concentración de población obrera podía agudizar los problemas de salubridad y, por ende, la conflictividad. Como la mayoría de las grandes ciudades, Barcelona buscó soluciones urbanísticas que, de acuerdo con el Plan Cerdá, supusieron el derribo de las murallas y el ensanche de la ciudad con la consiguiente ganancia de espacios libres y la conexión con el mar. Fue en esos momentos cuando las miradas se dirigieron a las sociedades anglosajona y francesa cuyo despliegue de servicios en torno al cuidado del cuerpo (balnearios, sanatorios de reposo, zonas de veraneo, prácticas de sport al aire libre, baños de mar, gimnasios, etc.) constituyeron un punto de inflexión cultural.

Pero en el uso de los nuevos espacios urbanos entraba también en juego el deseo, más o menos premeditado, de consolidar una identidad social, la burguesa, para la que una corporalidad recreativa y ociosa, desprendida de los rasgos más visibles de lo utilitario -al menos aparentemente-, se presentaba como un baluarte. $Y$ decimos aparentemente porque, la cuidada atención a la recreación física y al ocio — cada vez más próxima a las ideas de higiene y salud- empezaba a cobrar importancia como valor económico.

Así pues, en los gimnasios de Barcelona asistían jóvenes que iban para reparar su salud, por convicción higiénica, pero también movidos por el impulso de la moda recreativa como forma de autoafirmación. A este respecto, aunque a los gimnasios higiénicos privados acudían también usuarios de capas sociales menos acomodadas, con el objeto de restaurar la salud perdida, los principales clientes pertenecían al sector más pudiente cuyas luchas se libraban más en el campo simbólico que en el propiamente físico.

Pero, además de las diferencias culturales, una de las barreras sociales impuestas al uso común del gimnasio era la pecuniaria puesto que las cuotas de ingreso al gimnasio no estaban al alcance de cualquiera siendo que el sueldo de un obrero apenas alcanzaba para los gastos básicos de subsistencia. Por ejemplo, en 1867 el jornal de un obrero soltero era de 8,556 reales/día, y los gastos para su manutención alimenticia estaban estimados en 4,26 reales/día (Cerdá 1867: 656).

Uno de los aspectos más singulares del proceso de conformación de la gimnástica higiénica decimonóni- 
ca y de las identidades sociales que la acompañan es el que tiene que ver con el afianzamiento de la masculinidad - tras no pocos titubeos - hacia las formas del vigor y la rectitud, la virilidad musculosa pero proporcionada; un arquetipo de corporalidad que penetró en España a través de la obra del krausista Julián Sanz del Río (1860) para quien el gimnasio — de raigambre grecolatina - debía ser el punto de encuentro de una nueva cultura de amor al propio cuerpo forjada sobre la tríada salud, fuerza y belleza; una tríada según la cual la estética del desnudo masculino había de representar la perfección del cuerpo, un «nuevo hombre» para la humanidad que pudiera garantizar a través del matrimonio «... una generación sana, robusta y profunda» (Sanz del Río 1860: 85).

No poco importante para la configuración de este nuevo hombre serían la fijación de los dispositivos de la sexualidad (Seoane 2006; Vázquez y Cleminson 2011; Zubiaurre 2015) y, particularmente, tal como lo planteó Foucault (2012), el proceso de medicalización de las conductas sexuales:

Mientras el adolescente no tome parte en las distracciones y juegos de su edad, huya de la sociedad de sus compañeros, esté triste y ensimismado, tenga los ojos hundidos, cara demacrada, falta de fuerzas, desórdenes nerviosos viscerales, palpitaciones de corazón, etc., etc., y no haya causa apreciable que explique satisfactoriamente este estado de enervación, debe sospecharse la existencia de un hábito vicioso, repugnante en si mismo y funesto por sus consecuencias. La influencia depresiva de la inteligencia, el ataque directo a la inervación ganglionar, el empobrecimiento de la sangre, de que el onanismo es causa, se constituyen a su vez motivo de esa susceptibilidad nerviosa, de esa constitución delicada que predispone a toda clase de enfermedades y a las muertes prematuras por la tuberculosis. Por esto, nunca se encarecerá bastante la utilidad, la conveniencia, la imprescindible obligación de los padres y tutores de mantener una vigilancia esmerada cuando se sospeche un vicio de tanta trascendencia: y en caso, reprenderle severamente y sujetar al individuo a los trabajos corporales, á la equitación, a los ejercicios gimnásticos para gastar una actividad supérflua (Busqué 1865: 127).

En efecto, el gimnasio higiénico, que como dispositivo de identidad burguesa surgió al amparo de los discursos regeneracionistas, encontró en los «vicios» de la civilización un nuevo y convincente argumento: mediante la canalización de las energías, el ejercicio físico no solo proporcionaría un aspecto robusto y saludable al hombre sino que además le libraría de los «vicios femeninos» o de la homosexualidad tal como planteaba, por ejemplo, Lladó (1868: 111): «No creo necesario aquí hablar de la influencia inmensa que el ejercicio tiene en la juventud para apartarla de vicios repugnantes; todos los higienistas, todos los médicos lo indican para que unido á los consejos religiosos produzca saludables resultados».

Y nada mejor que acudir a la propia experiencia para corroborar la tesis: por recomendación del Dr. Santiago Méndez Lladó, que tenía un cuerpo débil y enfermizo, asistió a la edad de veinte años al gimnasio de los hermanos Vall. La rápida recuperación que obtuvo le sedujo de las tantas utilidades que podía reportarle la gimnástica que «... por esto he aconsejado siempre la gimnástica, especialmente á los jóvenes endebles y enfermizos que como yo han hallado en el ejercicio el remedio que en vano habían buscado en la medicina» (Lladó 1868: 8). Pero Lladó no solo encontró en la gimnástica el remedio a su debilidad física; en la disciplina que esta encarnaba encontró también el mejor acomodo para los códigos morales más beligerantes del regeneracionismo como, por ejemplo, los que se articulaban en torno a la idea de feminización de la cultura: «la afeminación y de la molicie que hacen al hombre endeble y engendran el vicio, causas que influyen notablemente en la debilidad é impotencia de las naciones» (Lladó 1868: 110). Y es que, como señalaba Mosse (2000: 56), «el contraste entre hombre varonil y afeminado estuvo presente a lo largo de todo el proceso de construcción de la masculinidad moderna»; la imagen de la mujer en el siglo XIX era, todavía, la perturbadora imagen de la maldad (Zubiaurre 2015).

Pero el sello conceptual de la "afeminación» de la sociedad o del hombre tuvo durante el siglo XIX un amplio espectro de significaciones; tanto valía para referirse a las conductas amaneradas y sentimentales como a la pederastia o a la sodomía (Vázquez y Cleminson 2011):

El hombre afeminado, aquel que como la más remilgada dama pasa horas enteras en el tocador, que teme a exponerse á los rayos del sol para que no alteren la blancura de su tez, que echa mano de todos los cosméticos preconizados para suavizar el cutis, es siempre mirado con desdén sino con desprecio por los demás; parece que no es digno de ser hombre (Lladó 1868: 111).

Asimismo, por afeminación podía entenderse afectación del llamado temperamento nervioso (Mosse 2000); algo propio de mujeres y de niños, víctimas 
de la vida moderna, y que se manifestaba en los varones como una enfermiza falta de valor, es decir, denotaba cobardía y pusilanimidad:

El temperamento nervioso, es propio y peculiar de las grandes ciudades, en que el lujo, la corrupción de las costumbres y la excesiva civilización oscurecen las virtudes morales y olvidan los frenos impuestos á la sociedad en tiempos más remotos, se alambican los placeres y las sensaciones, que no excitan ya a organismos depauperados desde la cuna. Los literatos, los artistas, los hombres de bufete, los afeminados, nuestros modernos dandis, los que se entregan con exceso al uso o abuso de la Venus, los valetudinarios, las victimas de afecciones morales y de grandes infortunios poseen con frecuencia este desgraciado temperamento (Mellado 1855: 1062).

Asumiendo los discursos procedentes del centro y el sur de Europa (Torrebadella-Flix y Vicente-Pedraz 2016), los prosélitos de la gimnástica española coincidían en que la buena dirección de los ejercicios gimnásticos desarrollaba el instinto viril y la valentía a la vez que evitaba uno de los peores males del siglo: el onanismo.

Contra el temperamento nervioso, al igual que contra el vicio autoerótico, para los que antes se recomendaba el ejercicio intenso como la caza, la equitación, la esgrima o la natación, empezaba a presentarse la gimnástica como un eficaz medio indudablemente más accesible que los anterioresde cambiar el carácter o de curar el vicio, de hacer al hombre más hombre:

Bajo la influencia de la gimnástica el hombre de temperamento nervioso cambia sus formas delicadas, el color pálido o térreo de su cutis y su impresionabilidad, en ese desarrollo muscular envidiable, en esa piel curtida y colorada en esa regularidad y constancia de los actos nerviosos, atributos característicos del temperamento muscular o sanguíneo (Busqué 1865: 102).

Pero en el gimnasio también se cincelaba el cuerpo femenino. La corrección de las conformaciones llamadas viciosas consideradas femeninas, como la escoliosis, eran también objeto de la gimnástica higiénica que, en este caso, además de la estética del cuerpo erguido, esbelto y proporcionado, se tomaba el cuidado de subrayar la importancia de la maternidad en la buscada regeneración del hombre (Torrebadella-Flix 2011a). Ahora bien, siempre considerando que el cuerpo de la «mujer es más débil y sería un absurdo el querer que tuviese formas hercúleas y mirara la gimnasia bajo el punto de vista de la fuerza» (Lladó 1868: 26):

Mirado bajo el punto de vista moral el ejercicio tiene mucha trascendencia para la mujer, especialmente para que merced a su holgada posición apenas se dedica a trabajos domésticos. El ocio la hace endeble, y cuando llega a ser madre le falla a veces el vigor suficiente para ello, y para dotar al nuevo ser de una constitución robusta (Lladó 1868: 125).

A este respecto, se puede decir que el éxito de los gimnasios higiénicos estuvo también asociado al desarrollo del cuerpo femenino saludable, pero bajo la supervisión de un estricto control médico donde la frontera entre lo biológico y lo moral estaba totalmente desdibujada:

El bello sexo tiene en su patología especial dos enfermedades que se originan en la evolución ó del predominio excesivo del útero tales son la clorosis y el histerismo. Un estudio detallado de ambas dolencias de lugar indispensable (Busqué 1865: 127).

En todo caso, y pese al encorsetamiento físico y moral que las prácticas gimnásticas imponían, estas también dotaban al cuerpo de una cierta simbología en la que la insinuación hedonista prendía con facilidad. A contrapelo del cuerpo ascético, aceptado socialmente sin fisuras, el esparcimiento recreativo al que invitaba el gimnasio a sus usuarios más distinguidos, junto con la estética de la semidesnudez, iría ganado terreno en lo que se podría considerar un elemento determinante en la configuración de un nuevo culto al cuerpo; la (moderna) resurrección de la carne de la que hablaba Ortega y Gasset (1987).

Los establecimientos gimnásticos constituyeron un espacio nuevo, de alguna forma cerrado sobre sí mismo, en el que el hombre se construía de acuerdo con un ideal de masculinidad que evocaba la estética corporal grecolatina, aunque modernizada (Mosse 2000). Además de la gimnástica atlética, también se propagaron otras prácticas como la esgrima, la lucha, el pugilato o la natación, que pronto pasarían a formar parte del programa de ejercitaciones saludables. Lo que había ocurrido en el gimnasio de Eugenio Paz en París, punto de encuentro de la alta sociedad (Paz 1867) o en los gimnasios ingleses - cuyos maestros de training hacían que en pocos meses los individuos enclenques se encontrasen en disposición de "correr velozmente, y durante largo tiempo sin fatigarse lo más mínimo... o luchar con el campeón más diestro y más robusto» (Debay 1874: 192)—, empe- 
zaba a tener lugar en los gimnasios españoles y particularmente, como avanzadilla, en los de Barcelona.

La imagen del torso desnudo del varón, musculoso y proporcionado se mostró como el paradigma de la salud, virilidad y de la perfección. Es el nacimiento del Homo gymnasticus en cuya constitución hay poco margen para la figura femenina (Scharagrodsky 2011). Frente a la estética del espacio compartido en los bailes de sociedad, los paseos e incluso en muchas escenas del naciente sport, el gimnasio se configuró como un espacio restringido al goce estético de la masculinidad. El posado desnudo del gimnasiarca más famoso de Francia Hippolyte Triat: «Esclave près d'un tombeau dans la campagne romaine» de Ernest Hebert, es un ejemplo de la estética que promueve la nueva corporalidad (Figura 3).

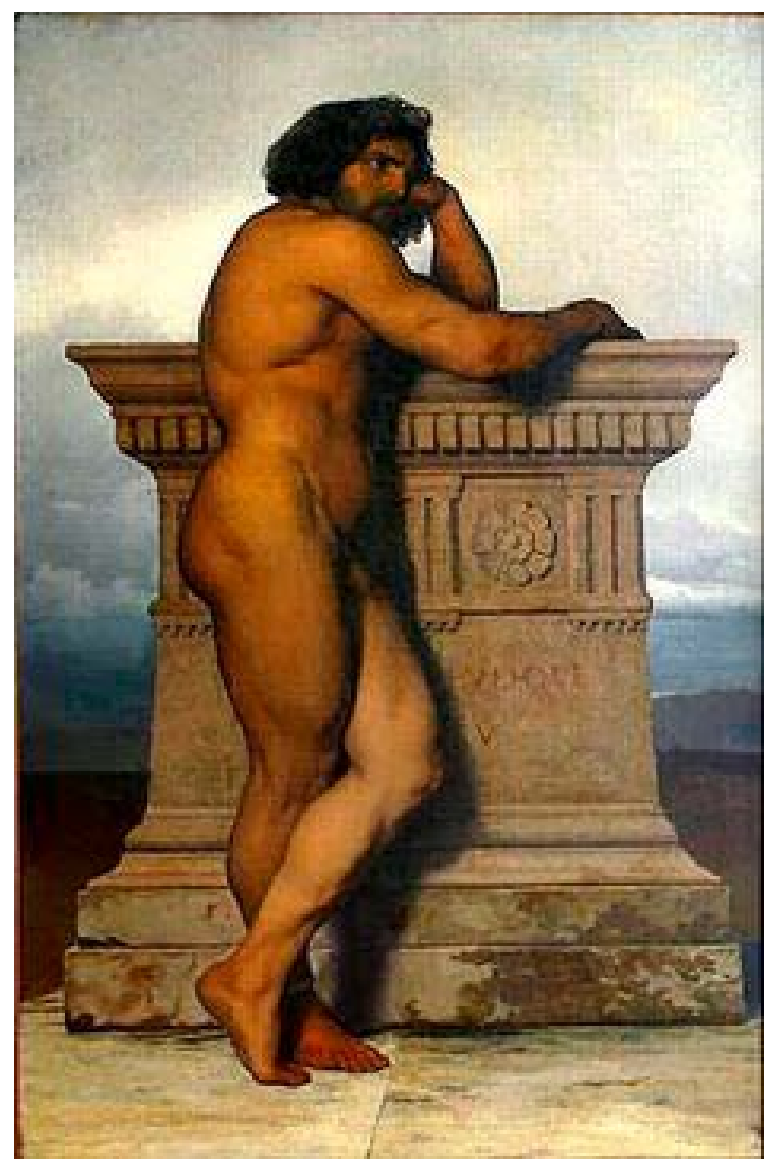

FiguRA 3.-Hippolyte Triat: Esclave près d'un tombeau dans la campagne romaine de Ernest Hebert

No obstante, en esta estética, es preciso poner de relieve cómo durante el período romántico especialmente la literatura puso al descubierto otras formas de aprecio de la corporalidad, diríase más femenina; una corporalidad donde la sensibilidad y lo sentimen- tal hicieron acto de presencia. $Y$ es que como dice García Valdés (1981: 76) los románticos estaban «dotados de una hipersensibilidad, para algunos poco viril», que les hacía abandonar lo práctico y lo cotidiano para embarcarse en la aventura de la libertad de la conciencia. Precisamente, en virtud de esa libertad, el romanticismo desafió los cánones estéticos y también morales de la sociedad decimonónica; un desafío que se expresaba, entre otros muchos aspectos, en la consideración que empezaron a recibir las formas no convencionales, o no dominantes, de la sexualidad y, particularmente, una consideración de la homosexualidad cada vez más alejada del enjuiciamiento criminal o del análisis clínico (Tardieu 1863) ${ }^{4}$. De ahí que la noción de sodomía empezara a reconstruirse en el imaginario social de acuerdo con el antiguo «amor ático a la gimnasia» (Selva 1870: 206).

Pero también en este campo la consideración social variaba en función de la clase social. La burguesía gozaba del privilegio de la doble moral de modo que aunque de manera silenciosa, entre ellos la homosexualidad era admisible. No, en cambio, para las clases medias y el proletariado para cuyos miembros el amor entre hombres era reducido con internamiento en presidio o en centros para dementes.

Cabe destacar a este respecto cómo el influyente higienista Pedro Felipe Monlau, promotor de la higiene social en la España de mediados del XIX y artífice de una verdadera biopolítica de la ejercitación gimnástica obrera (Vicente-Pedraz y Torrebadella-Flix 2017: 9-10), señalaba que el celibato voluntario de los hombres equivalía a una plaga para el Estado que debía ser combatida por el Gobierno, puesto que engendraba la ruina y la decadencia social y del Estado:
el celibato que reconoce por causa la miseria pú- blica o la corrupción general, es una verdadera epidemia, y epidemia tanto más terrible en cuanto ligada con otras cien calamidades, casi nunca pue- de ser combatida con buen éxito, o de una manera perentoria (Monlau 1858: 55).

En todo caso, el gimnasio se ofrecía como auxilio a los hombres al intervenir desde la juventud en la reparación de «... la masturbación, especie de enfermedad sin dolor, pero vicio odioso y funesto que trae

4 La palabra homosexual aparece citada en 1869 un texto del activista prusiano Karl-Maria Kertbeny (1824-1882), el cual sostenía que la homosexualidad tenía un origen innato, y que por lo tanto, no podía criminalizarse como una conformación viciosa adquirida. Véase Zubiaur (2007). 
de seguro la ruina del cuerpo y la perdición del alma» (Monlau 1858: 522) según un pensamiento que asumió la mayor parte de los higienistas y gimnasiarcas: «... solo la gimnasia llevada hasta la fatiga, no tenemos inconveniente alguno en declararlo, es el único remedio que victoriosamente se le puede oponer» (Paz 1867: 21). Tal era la importancia del asunto que la gimnástica, y a veces de los deportes, fueron distinguidos como el mejor antídoto contra las «perversiones» de la civilización: desde el apoltronamiento y la molicie hasta el onanismo, pasando por la homosexualidad, en un denodado intento de preservar a la sociedad de los peligros que estos representaban (Vázquez y Cleminson 2011; Chaline 2015).

En este sentido, el gimnasio higiénico no solo fue un foro de experimentación de usos y representaciones del cuerpo saludable al que aspiraba la burguesía como seña de identidad; también se constituyó como un dispositivo de la heterosexualidad decimonónica en la medida en que aparecía como espacio para el cultivo y, en su caso, recuperación de la masculinidad. Incluso aquí los promotores de los gimnasios higiénicos supieron hacer acopio de los eslóganes que la medicina había acuñado respecto de la sexualidad y que se materializaba en una obsesiva persecución de cualquier manifestación que pusiera en riesgo los baluartes de la heterosociedad.

Pero es de suponer que el gimnasio, en tanto espacio de reunión principalmente de varones, se mostró propicio para albergar, más o menos clandestinamente, una cierta subcultura homoerótica (Vázquez García 2001). A este respecto, la imagen idealizada del Homo gymásticus, virilmente hercúleo, no siempre respondía a las expectativas creadas.

Véase al respecto la semblanza que se hizo del Dr. Eduardo Tolosa Alsina, profesor titulado en la Escuela Central de Gimnástica (1887-1892) e hijo del ya citado Pedro García Corbera, fundador del Gimnasio de Gracia en 1868.

Eduardo Tolosa. Director del Gimnasio-recreativo para ambos sexos, con departamentos separados, cuartos de duchas y de masaje (galicismo) sala de armas y cuantas derivaciones de conocen en Gimnasia, es una contradicción notoria, una antítesis completa.

Al saber que se halla al frente de un tan vasto establecimiento, cualquiera que no lo conozca supondrá que es de elevada estatura, enjuto de carnes, de tez morena, ojos pequeños y penetrantes, movimientos rápidos y fuerza hercúlea, en una palabra, un antiguo lacón revivido, un austero espartano; y sin embargo es realmente todo lo contrario. De baja estatura, cutis aterciopelado como el de una joven valenciana, más bien grueso que delgado, ojos grandes y expresivos, tez blanca, de constitución delicada y maneras afeminadas, parece que la naturaleza ha errado al dotarle de sexo masculino y que él también ha errado al escoger la carrera de Gimnasia, tan contraria a sus condiciones físicas.

Lejos de ser un atleta, un Hércules moderno, es más bien el nuevo Cupido que se atrae las miradas femeninas; y penetrado de sus cualidades estéticas, así como el antiguo Narciso contemplaba su hermosura en las cristalinas aguas del arroyo, Tolosa, como nuevo Narciso, cuando habla con otra persona, si hay un espejo, a éste mira y no a la persona, y no deja de atusarse su sedoso bigote y de arreglarse con sus delicadas y blancas manos la corbata de la manera que imprima más gracia a su hermoso semblante.

Es un hombre completamente feliz. Cualquier otro hubiera fracasado en su colosal empresa, pero él ha logrado coronarla de favorable éxito. Hombre de gusto estético y necesitado por naturaleza de halagos y caricias, supo escoger por compañera una mujer hermosa, y no solamente goza de su dulce y amable compañía, sino también de la de su hermana política no menos bella y cariñosa» (Garriga 1894: 1).

En todo caso, si el proceso de conformación del comportamiento moderno tiene, de acuerdo con Elias (1987), algo de adorno y refinamiento -como mecánica de la diferenciación-, dicho proceso remite inevitablemente a cierta forma de feminización de las relaciones interpersonales en el sentido de que impone formas progresivamente más elaboradas de la conducta y, en este caso, de la conducta corporal. En efecto, a la vez que se configura el arquetipo del Homo gymnásticus como paradigma de una cultura masculina y masculinizante, de forma inseparable tiene lugar la configuración de la feminidad burguesa cuya lenta pero continua impregnación cultural se ponía de relieve en la estilización del gesto y de los gustos, en la afectación del lenguaje, en el aliño del vestido, etc.

A ese respecto, masculinidad y feminidad se verán involucrados a una pugna simbólica, a veces velada, a veces manifiesta, que particularmente se observa en el gimnasio del XIX en tanto que espacio que representaba la modernidad; espacio de confluencia de lo más granado de la sociedad donde, de algún 
modo, se ponían a prueba sensibilidades y formas de actuar.

\section{A MODO DE CONCLUSIÓN}

En el ambiente de ebullición cultural, artística, científica, tecnológica que recorre buena parte de Europa al calor de la eclosión burguesa del siglo XIX, el cuerpo empezó a cobrar un importante valor simbólico. Más allá del desarrollo de los renovados cuidados higiénicos y médicos, aunque amparados y legitimados por estos, el cuerpo no solo se perfiló como dispositivo de control - como el blanco de poder que tan certeramente enunció Foucault-, sino que también se configuró como un poderoso mecanismo distintivo: a la vez de individualización (personal) y de diferenciación (de clase). No cabe duda de que el cuerpo siempre ha operado, al menos en la cultura occidental, como mecanismo de distinción; pero lo que en otro tiempo no era sino un elemento más de la escenografía social que ponía de relieve las diferencias previamente constituidas (sobre todo por linaje), en ese momento $-y$ de manera exponencialmente creciente hasta ahora - el trabajo sobre el cuerpo se constituyó en un verdadero trabajo sobre la identidad. Y no solo por los resultados de dicho trabajo (regularidad, rectitud, armonía, etc.), aunque también por ellos, sino fundamentalmente por lo que social y culturalmente significaba ocuparse electivamente del cuerpo - dedicarle tiempo y esfuerzo-, para aquellos que, en todo caso, podían ocuparse de él, de la manera en que lo hacían en el gimnasio.

Disciplinamiento e individualización-diferenciación mediante un trabajo sobre el cuerpo, más o menos aliñado con ingredientes recreativos según las circunstancias, constituían el haz y el envés de un proceso de refinamiento (civilizatorio) de las costumbres que, tal como planteaba Elias (1987), estaba inseparablemente unido al desarrollo de mecanismos de autocontrol. Si como decía Elias, el motor de la civilización es la permeabilidad de las costumbres que se dan en vida en común, espoleada por las tendencias de autoafirmación, entonces el gimnasio higiénico del siglo XIX fue un importante dispositivo civilizatorio particularmente representativo de la cultura burguesa. Un dispositivo que en la medida en que se fue extendiendo a otras capas sociales, como consecuencia de la tendencia a la promoción social a través de la apariencia, cumpliría con la pauta homogeneizadora propia de las sociedades modernas.

\section{BIBLIOGRAFÍA CITADA}

Aguilera, Francisco. 1865. «Reseña histórica del Gimnasio Real de Madrid. Observaciones y explicaciones sobre los objetos originales y los de mayor importancia que contiene». Revista de Sanidad Militar Española y Extranjera Médicas 25 abr.: 197-203.

Andrieu, Gilbert. 1992. Force et beauté. Histoire de l'esthétique en Education Physique aux XIXe et XXe siècles. Burdeos: Presses Universitaires de Bourdeaux.

Bourdieu, Pierre. 1986. «Notas provisionales sobre la percepción social del cuerpo», en Julia Varela y Fernando ÁlvarezUría, Materiales de sociología crítica: 183-194. Madrid: La Piqueta.

Bourdieu, Pierre. 1988. Cosas dichas. Buenos Aires: Gedisa.

Busqué, Sebastián. 1865. Gimnástica higiénica, médica y ortopédica o el ejercicio considerado como medio terapéutico. Madrid: Imp. Manuel Galiano.

Carlier, Pedro. 1867. Tratado de gimnasia médica y civil. Santander: González.

Cercós, Raquel y Ángel C. Calvo. 2013. «La subversión del gentleman. Cuerpo y belleza en el ethos victoriano". Revista de Historia de la Educación 32: 105-119.

Cerdá, Ildefonso. 1867. Teoría general de la urbanización... Tomo II: La urbanización considerada como un hecho concreto: estadística urbana de Barcelona. Madrid: Imp. Española.

Chaline, Eric. 2015. The Temple of Perfection: A History of the Gym. Londres: Rakition Books.

Climent, José María. 2001. Historia de la rehabilitación médica. De la física terapéutica a la reeducación de inválidos. Barcelona: Edika Med.

Coca y Cirera, Antonio. 1862. Tratado de terapéutica general. Barcelona: Imp. Diario de Barcelona.

«Colegio Mataronés». 1864. El Monitor de primera enseñanza 10 sep.: 295.

Cruz Valenciano, Jesús. 2014. El surgimiento de la cultura burguesa. Personajes, hogares y ciudades en la España del siglo XIX. Madrid: Siglo XXI de España Editores.

Dally, Nicolas. 1848. Gymnastique. De la régénération physique de l'espèce humaine par la gymnastique rationelle. París: Imp. Paul Dupont.

Dalmau, Antonio R. 1947. El circo en la vida barcelonesa. Crónica anecdótica de cien años circenses. Barcelona: Ediciones Librería Milla.

De Andrés, S. 1858. "Higiene, o medios de conservar la salud y los órganos». El Consultor Higiénico 18 ene.: 17-20.

De Certeau, Michel de. 2000. La invención de lo cotidiano. México: Universidad Iberoamericana.

Debay, Auguste. 1874. Historia natural del hombre y de la mujer. Barcelona: Jané Hermanos.

«Diversiones públicas». 1863. El Lloyd Español 11 abr.: 4. 
Donzelot, Jacques. 1998. La policía de las familias. Valencia: Pre-textos.

Elias, Norbert. 1987. El proceso de la civilización. Madrid: Fondo de Cultura Económica.

Elias, Norbert. 1990. La sociedad de los individuos. Barcelona: Península.

Fernández Losada, Cesáreo. 1865. «Gimnasio para instrucción del Sermo. Sr. Príncipe de Asturias y de SS. AA. RR., dirigido por el Sr. Conde de Villalobos». Revista de Sanidad Militar Española y Extranjera 2: 192-196.

Ferrer y Mitayna, David. 1901. «(Biografía)». Los Deportes 19 may.: $316-318$

Féval, Paul. 1852. «El palacio gimnástico. Gimnasio Central de París». La Nación 17 oct.: 2-3.

Foucault, Michel. 2005. Vigilar y castigar. Madrid: Siglo XXI.

Foucault, Michel. 2012. Historia de la sexualidad. 1 La voluntad del saber. Barcelona: Siglo XXI.

García Valdés, Alberto. 1981. Historia y presente de la homosexualidad. Madrid: Akal.

Garriga, Ramón Manuel. 1894. Semblanzas gimnásticas. Barcelona: Tip. de la Casa Provincial de la Caridad.

«Gimnasia». 1858. La España 7 mar.: 1.

Goux, Juan. 1864. Algunas consideraciones sobre la educación física del hombre en general y particularmente sobre el método de Juan Goux. Madrid: Imprenta de Manuel Bernardo Quirós.

Goux, Juan. 1866. Algunas palabras sobre la gimnástica médica y ortopédica. Madrid: Establecimiento Tipográfico de T. Fortanet.

Gurrera i Lluch, Montserrat. 1995. «L'educació física als primers butlletins del Col-legi Valldemia (1868-1972)». Fulls de Museo Arxiu de Santa Maria 51: 16-24.

Heiser, Chrétien. 1854. Traité de gymnastique raisonnée, au point de vue orthopédique, hygiénique et médical; ou Cours d'exercices appropriés a l'éducation physique des deux sexes et applicables a tous les ages. París: Victor Masson.

J. A. de T. 1868. El Principado 4 feb.: 804-805.

J. A. S. y M. LI. 1863. El Consultor, nueva guía de Barcelona. Barcelona: Establecimiento Tipográfico de Narciso Ramírez.

"La regeneración física de la especie humana por medio de la gimnasia racional». 1848. El Clamor Público 8 abr.: 2-3.

Lladó, Joaquín. 1868. Nociones de gimnástica higiénica, aplicables a las escuelas de instrucción primaria de uno y otro sexo como elementos de educación física. Barcelona: Librería de Juan Bastinos e Hijo.

López Gómez, Salvador. 1873. El gimnasio. Tratado teóricopráctico de todos los principios y reglas de aplicacion á esta importante parte de la higiene. Sevilla: R. Baldaraque.

Macedo, L. A. de. 1860. "Algunas consideraciones acerca de la gimnástica». La España Médica 5: 21-22.
Masriera Colomer, Arturo. 1924. Los buenos barceloneses: Hombres, costumbres y anécdotas de Barcelona ochocentista (1850-1870). Barcelona: Ed. Poliglota.

Mellado, Francisco de Paula. 1855. Enciclopedia moderna: Diccionario Universal de literatura, ciencias, artes..., tomo 32. Madrid: Establecimiento de Mellado.

Monlau, Pedro Felipe. 1858. Higiene del matrimonio ó El libro de los casados. Madrid: Manuel Rivadeneyra.

Moratones, Antonio. 1863. Nociones elementales de gimnasia, para jóvenes de ambos sexos... Barcelona: Imp. Joaquín Bosch.

Mosse, George L. 2000. La imagen del hombre. La creación de la moderna masculinidad. Madrid: Talasa.

Nanu, Irina y Miguel Vicente Pedraz. 2007. «Qual deve seer el rey a sus fijos e ellos a él. Disciplina exterior y disciplina interior en el título VII de la Segunda Partida de Alfonso X el Sabio». Romance Philology 61(2): 213-234.

Ortega y Gasset, José. 1987. "Vitalidad, alma, espíritu (El espectador V)", en José Ortega y Gasset, Obras Completas II. Madrid: Alianza Editorial.

Paz, Eugenio. 1867. La salud del espíritu y del cuerpo por la gimnasia. Murcia: Imprenta de Anselmo Arques.

Piernavieja, Miguel. 1962. "Antecedentes histórico-legales de la Educación Física en España». Citius, Altius, Fortius 4(1): 5-150.

Planella Ribera, Jordi. 2006. Cultura, cuerpo y educación. Bilbao: Desclée de Brouwer.

Pujadas i Martí, Xavier. 2010. «De las élites a las masas: Deporte y trasformación de las formas de ocio moderno en Cataluña (1890-1936)", en Xavier Pujadas i Martí (coord.). La metamorfosis del deporte. Investigaciones sociales y culturales del fenómeno deportivo contemporáneo: 19-39. Barcelona: Editorial Universitat Oberta de Catalunya.

R. F. 1882. «Revista de Gimnasios». El Gimnasta Español 1 jul.: $1-2$.

Ramis Taix, Joaquín. 1865. Una verdad o consideraciones sobre la utilidad de la Gimnástica. Barcelona: Imprenta de Gómez e Inglada.

Ribes, François. 1860. Tratado de higiene terapéutica o aplicación de los medios de la higiene al tratamiento de enfermedades. Madrid: Imprenta de Manuel Álvarez.

Ronquillo, Carlos. 1870. Educación higiénica de un pueblo. Discurso leído en la sesión pública de la Sociedad Barcelonesa de Amigos de la Instrucción celebrada el día 28 de noviembre de 1869. Barcelona: Imprenta de Hijos de Domench.

Salgado y Valdés, Mariano. 1865a. «Gimnasio Real de Madrid». La España Médica 512: 462-465.

Salgado y Valdés, Mariano. 1865b. «Gimnasio Real de Madrid». La España Médica 513: 474-476

Sánchez y González de Somoano, José. 1884. Propaganda gimnástica. Madrid: Imprenta de Minuesa de los Ríos. 
Sanz del Río, Julián. 1860. El Ideal de la Humanidad para la Vida. Madrid: Imprenta de Manuel Galiano.

Scharagrodsky, Pablo A. 2011. La invención del homo gymnasticus. Buenos Aires: Prometeo.

Schreber, Daniel Gottlob Moritz. 1861. Manual popular de gimnasia de sala médica e higiénica. Madrid: Carlos BaillyBailliere.

Selva, Narciso Buenaventura. 1870. Comentarios al Código penal reformado y planteado provisionalmente por ley de 3 de junio de 1870. Madrid: Imprenta Española.

Seoane, José B. 2006. El placer y la norma: genealogía de la educación sexual en la España contemporánea: orígenes (1800-1920). Barcelona: Octaedro.

Spencer, Herbert. 1861. Education: Intellectual, Moral, and Physical. Londres: Williams and Norgate.

«Sueltos». 1882. El Gimnasta Español 15 dic.: 4-5.

Tardieu, Ambroise. 1863. Estudio médico-forense de los atentados contra la honestidad. Madrid: Imprenta Médica de Manuel Álvarez.

Torrebadella-Flix, Xavier. 2011a. «La educación física y la actividad gimnástico-deportiva de las mujeres a partir de la bibliografía especializada del siglo XIX». Arenal 18(1): 147179.

Torrebadella-Flix, Xavier. 2011b. Repertorio bibliográfico inédito de la educación física y el deporte en España (1800-1939). Madrid: Fundación Universitaria Española.

Torrebadella-Flix, Xavier. 2012a. «Antecedentes en la institucionalización de la gimnástica militar española (18001852)». Revista de Historia Militar 111: 185-244.

Torrebadella-Flix, Xavier. 2012b. «Las primeras tesis doctorales de la educación física en el espacio científico y profesional sobre la medicina española». Pecia Complutense 16: 58-88.

Torrebadella-Flix, Xavier. 2013a. «Crítica a la bibliografía gimnástica de la educación física en España (1800-1939)». Anales de Documentación 16(1).

doi: <https://doi.org/10.6018/analesdoc.16.1.158851>

Torrebadella-Flix, Xavier. 2013b. «Del espectáculo acrobático a los primeros gimnasios modernos. Una historia de las compañías gimnástico-acrobáticas en la primera mitad del siglo XIX en España». Aloma 31(2): 67-84.

Torrebadella-Flix, Xavier. 2013c. Gimnástica y educación física en la sociedad española de la primera mitad del siglo XIX. Lleida: Servei de Publicacions de la Universitat de Lleida.

Torrebadella-Flix, Xavier. 2014a. "La educación física comparada en España (1806-1936)». Historia Social y de la Educación 3(1): 25-53.

Torrebadella-Flix, Xavier. 2014b. «La influencia de la profesión médica en la educación física española del siglo XIX: Análisis social del Manual popular de gimnasia de sala, médica e higiénica del Dr. Schreber». Cultura, Ciencia y Deporte 9(26): 163-176.
Torrebadella-Flix, Xavier y Fernando Arrechea Rivas. 2015. Los orígenes de una ciudad olímpica. La vida gimnástica-deportiva en la Barcelona decimonónica. Madrid: Centro de Investigaciones de Historia y Estadística del Fútbol Español, CIHEFE.

Torrebadella-Flix, Xavier, Javier Olivera-Betrán y Mireia M-Bou 2015. "Origin and Institutionalisation of Sports and Gymnastics Associations in Nineteenth-Century Spain (18221900)». Apunts. Educación Física y Deportes 119: 7-54.

Torrebadella-Flix, Xavier y Miguel Vicente-Pedraz. 2016. «La gimnástica como dispositivo antionanista en la conformación de la educación física escolar en el siglo XIX en España. El nacimiento de una disciplina escolar». Movimento 22(1): 99-114.

Ugarte Pérez, Javier. 2012. «La matriz del deseo: del género a lo genital». Ayer 87(3): 23-44.

Vall, M. 1865. «Gimnasio Modelo». La Corona 3 mar.: 4.

Vázquez García, Francisco. 2001. «El discurso médico y la invención del homosexual (España 1840-1915)». Asclepio 53(2): 143-161.

Vázquez García, Francisco y Richard Cleminson. 2011. Los invisibles: Una historia de la homosexualidad en España, 18501939. Granada: Comares.

Vicente-Pedraz, Miguel y María Paz Brozas. 2017. «El triunfo de la regularidad: gimnasia higiénica contra acrobacia en la configuración de la educación física escolar en la segunda mitad del siglo XIX». Revista Brasilera do Sporte 39(1): 4955. doi: <http://dx.doi.org/10.1016/j.rbce.2015.10.006>.

Vicente-Pedraz, Miguel y Xavier Torrebadella-Flix. 2015. «La gimnástica como dispositivo antionanista en la conformación de la educación física escolar en el siglo XIX en España. Recepción de los discursos». Movimento 21(4): 1037-1049. doi: <https://doi.org/10.22456/1982-8918.53986>.

Vicente-Pedraz, Miguel y Xavier Torrebadella-Flix. 2017. «El dispositivo gimnástico en el contexto de la medicina social decimonónica española. De las políticas higiénicas a los discursos fundacionales de la educación física». Asclepio 69(1): 172. doi: <http://dx.doi.org/10.3989/asclepio.2017.04>.

Vigarello, George. 2005. Corregir el cuerpo. Historia de un poder pedagógico. Buenos Aires: Nueva Visión.

Vigarello, George. 2006. Lo sano y lo mal sano. Historia de las prácticas de la salud desde la Edad Media hasta nuestros días. Madrid: Abada Editores.

Vigarello George y Richard Holt. 2005. «El cuerpo cultivado: gimnastas y deportistas en el siglo XIX», en Alain Corbin, Jean-Jacques Courtine y George Vigarello (coord.), Historia del cuerpo. Madrid: Taurus.

Zubiaur, Ibon. 2007. Pioneros de lo homosexual. K. H. Ulrichs, K. M. Kertbeny, M. Hirschfeld. Rubí: Anthropos.

Zubiaurre, Maite. 2015. Culturas del erotismo en España, 18981939. Madrid: Cátedra. 
